Braz J Med Biol Res, September 2011, Volume 44(9) 920-932

doi: 10.1590/S0100-879X2011007500104

Endothelial dysfunction in cardiovascular and endocrine-metabolic diseases: an update

A.P. Davel, C.F. Wenceslau, E.H. Akamine, F.E. Xavier, G.K. Couto, H.T. Oliveira and L.V. Rossoni

The Brazilian Journal of Medical and Biological Research is partially financed by

\section{虽CNPq}

da Ciência e Tecnologia

Institutional Sponsors

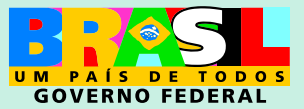

Q IAPESPP
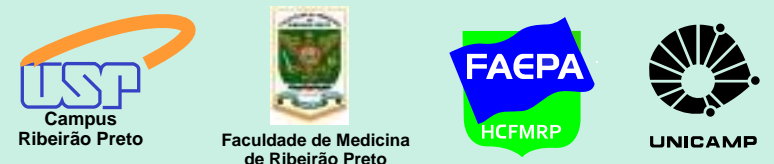

Ф SHIMADZU

Explore High - Performance MS In Proitrap Technology

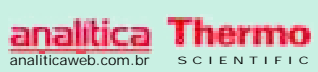




\title{
Endothelial dysfunction in cardiovascular and endocrine-metabolic diseases: an update
}

\author{
A.P. Davel ${ }^{3}$, C.F. Wenceslau ${ }^{1}$, E.H. Akamine ${ }^{2}$, F.E. Xavier ${ }^{4}$, G.K. Couto ${ }^{1}$, \\ H.T. Oliveira ${ }^{1}$ and L.V. Rossoni ${ }^{1}$ \\ ${ }^{1}$ Departamento de Fisiologia e Biofísica, ${ }^{2}$ Departamento de Farmacologia, \\ Instituto de Ciências Biomédicas, Universidade de São Paulo, São Paulo, SP, Brasil \\ ${ }^{3}$ Departamento de Anatomia, Biologia Celular e Fisiologia e Biofísica, \\ Instituto de Biologia, Universidade Estadual de Campinas, Campinas, SP, Brasil \\ ${ }^{4}$ Departamento de Fisiologia e Farmacologia, Centro de Ciências Biológicas, \\ Universidade Federal de Pernambuco, Recife, PE, Brasil
}

\begin{abstract}
The endothelium plays a vital role in maintaining circulatory homeostasis by the release of relaxing and contracting factors. Any change in this balance may result in a process known as endothelial dysfunction that leads to impaired control of vascular tone and contributes to the pathogenesis of some cardiovascular and endocrine/metabolic diseases. Reduced endotheliumderived nitric oxide (NO) bioavailability and increased production of thromboxane $\mathrm{A} 2$, prostaglandin $\mathrm{H} 2$ and superoxide anion in conductance and resistance arteries are commonly associated with endothelial dysfunction in hypertensive, diabetic and obese animals, resulting in reduced endothelium-dependent vasodilatation and in increased vasoconstrictor responses. In addition, recent studies have demonstrated the role of enhanced overactivation of $\beta$-adrenergic receptors inducing vascular cytokine production and endothelial NO synthase (eNOS) uncoupling that seem to be the mechanisms underlying endothelial dysfunction in hypertension, heart failure and in endocrine-metabolic disorders. However, some adaptive mechanisms can occur in the initial stages of hypertension, such as increased NO production by eNOS. The present review focuses on the role of NO bioavailability, eNOS uncoupling, cyclooxygenase-derived products and pro-inflammatory factors on the endothelial dysfunction that occurs in hypertension, sympathetic hyperactivity, diabetes mellitus, and obesity. These are cardiovascular and endocrine-metabolic diseases of high incidence and mortality around the world, especially in developing countries and endothelial dysfunction contributes to triggering, maintenance and worsening of these pathological situations.
\end{abstract}

Key words: Endothelial dysfunction; Hypertension; Sympathetic hyperactivity; Diabetes; Obesity

\section{Introduction}

Since the 1980s it has become clear that the endothelium is not only a monolayer that works as a physical barrier between blood and the underlying tissue, but also acts as an endocrine organ able to produce and release different metabolically active substances. Furchgott and Zawadzki (1), in 1980, showed for the first time that endothelial cells have an obligatory role during the relaxation induced by acetylcholine in isolated rabbit aorta. These investigators also demonstrated that acetylcholine activates muscarinic receptors in the endothelial cells and that this activation releases a substance then termed "endothelium-derived relaxing factor - EDRF" (1). Rapoport et al. (2) observed that endothelium-dependent vasodilators induce relaxation through cyclic GMP-dependent protein phosphorylation, similar to that observed with nitric oxide (NO) donors (e.g., sodium nitroprusside). Later, this EDRF was identified as NO by Ignarro et al. (3) and Palmer et al. (4). Physiologically, NO is synthesized from the amino acid L-arginine by the neuronal (nNOS or NOS I) and endothelial (eNOS or NOS III) nitric oxide synthase (NOS) enzymes. These isoforms are expressed constitutively and the active enzyme is part of a multi-protein complex forming the NOS dimer. The NOS dimer consists of an N-terminal oxygenase domain that contains binding sites for heme, L-arginine and tetrahydrobiopterin $\left(\mathrm{BH}_{4}\right)$, and a reductase domain with binding sites for nicotinamide adenine dinucleotide

Correspondence: L.V. Rossoni, Departamento de Fisiologia e Biofísica, ICB, USP, Av. Prof. Lineu Prestes, 1524, Sala 225, 5508-900 São Paulo, SP, Brasil. Fax: +55-11-3091-7285. E-mail: Irossoni@icb.usp.br

Presented at the XV Simpósio Brasileiro de Fisiologia Cardiovascular, São Paulo, SP, Brazil, February 2-5, 2011.

Received February 14, 2011. Accepted August 1, 2011. Available online August 19, 2011. Published September 16, 2011. 
phosphate (NADPH), flavin mononucleotide (FMN), flavin adenine dinucleotide (FAD), and calmodulin (CaM). Upon activation, the oxidase domain of the NOS isoforms produces $\mathrm{NO}$ from L-arginine using $\mathrm{O}_{2}$, requiring $\mathrm{BH}_{4}, \mathrm{NADPH}, \mathrm{FMN}$, and FAD as co-factors that maintain the NOS dimer structure and consequently the NO synthesis (5).

In addition to NO, it is well known that endothelial cells produce and release a series of metabolically active factors. Over the years, it has been shown that endothelium produces several EDRFs, as well as $\mathrm{NO}$, prostacyclin $\left(\mathrm{PGl}_{2}\right)$ and endotheliumderived hyperpolarizing factors (EDHFs). Endothelium also releases contractile factors (EDCFs), as well as angiotensin-II, endothelin-1, prostaglandins such as thromboxane $A_{2}\left(T x A_{2}\right)$, prostaglandin $\mathrm{H}_{2}\left(\mathrm{PGH}_{2}\right)$ and prostaglandin $\mathrm{F}_{2 \alpha}\left(\mathrm{PGF}_{2 \alpha}\right)$ and finally reactive oxygen species (ROS). Through a fine balance between the release of EDRFs and EDCFs, the endothelium plays a vital role in maintaining circulatory homeostasis. Any change in this balance may result in endothelial dysfunction.

Endothelial dysfunction is a pathological condition characterized by an imbalance between EDRFs and EDCFs. This imbalance is associated with changes in the synthesis, bioavailability and/or action of endothelial factors and results in reduction of endothelium-dependent vasodilatation and/or in an increased response to vasoconstrictor agonists. Thus, endothelial dysfunction impairs vascular function in cardiovascular diseases as well as in endocrine-metabolic disorders. Since endothelial cells produce and release many relaxing and contractile factors, extensive studies have analyzed the factors involved in endothelial dysfunction occurring in pathological conditions. The present review discusses some recent information concerning the role of endothelial dysfunction in hypertension, sympathetic hyperactivity, diabetes mellitus, and obesity, which are cardiometabolic diseases of high incidence and mortality around the world, especially in developing countries. We focused on the role of NO bioavailability, eNOS uncoupling, cyclooxygenase (COX)-derived products and the role of pro-inflammatory mediators in these cardiometabolic diseases.

\section{Endothelial dysfunction in hypertension}

Hypertension is a common disease that affects more than $40 \%$ of the adult population in developed countries and about $25 \%$ in emerging countries such as Brazil.According to the Brazilian Ministry of Health (6), the proportion of Brazilians diagnosed with hypertension increased from $21.5 \%$ in 2006 to $24.4 \%$ in 2009 . Hypertension is characterized as a medical condition in which blood pressure is chronically elevated and is of multifactorial origin. In this context, physiopathological mechanisms such as endothelial dysfunction present in the blood vessels might contribute to the genesis and/ or maintenance of hypertension.
Endothelial dysfunction is a hallmark of hypertension. However, the mechanisms underlying endothelial dysfunction differ among the experimental models of hypertension and the vascular beds studied. Two major functional changes have been frequently observed in the vasculature of hypertensive animals: an increased sensitivity to vasoconstrictor agents and/or a reduced endothelium-dependent relaxation induced by shear stress or agonists such as acetylcholine. These changes have been observed in different experimental hypertension models such as deoxycorticosterone acetate (DOCA)-salthypertensive rats (volume-dependent hypertension model), spontaneously hypertensive rats (SHR, a genetic model of hypertension that resembles the primary hypertension of humans), ouabaininduced hypertension (an endocrine model of hypertension dependent on the increment of plasma ouabain levels), among others (7-9). As shown in Figure 1, acetylcholine-induced relaxation was impaired in mesenteric resistance arteries from DOCA-salt hypertensive rats and SHR as compared to control normotensive rats. These changes have also been observed in hypertensive patients (10). Konishi and Su (7) first reported that endothelium-dependent acetylcholine-induced relaxation is impaired in aorta from SHR. After that, studies have focused on elucidating the possible pathways involved in this abnormality.

A decline in NO bioavailability in hypertension is one of the most common features of endothelial dysfunction. It can be triggered by reduced eNOS gene and protein expression, impaired eNOS phosphorylation at the serine 1177 residue, decreased availability of eNOS substrate or co-factors, mainly $\mathrm{BH}_{4}$, altered interaction between eNOS and caveolin-1, decreased antioxidant defense, and/or NO inactivation by ROS.
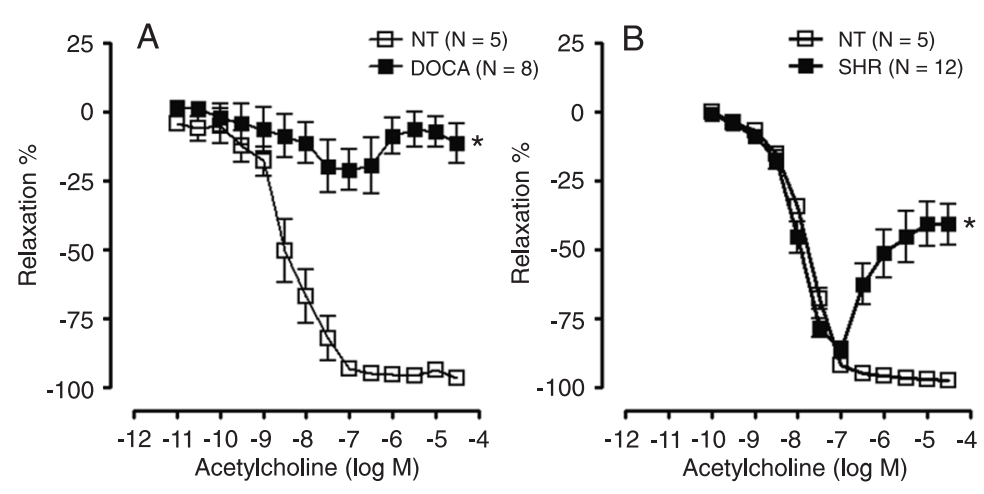

Figure 1. Endothelium-dependent relaxation induced by acetylcholine in mesenteric resistance arteries from adult ( 3 months old) DOCA-salt hypertensive rats (DOCA) $(A)$, spontaneously hypertensive rats (SHR) $(B)$ and normotensive male Wistar rats $(\mathrm{NT})(A, B)$. Note that the response elicited by acetylcholine in arteries from the DOCA and SHR groups is biphasic and induces contraction at high concentrations. DOCA-salt hypertension was induced in male Wistar rats submitted to uninephrectomy and treated for 8 weeks with DOCA $(20 \mathrm{mg} /$ $\mathrm{kg}$ in the first week, $12 \mathrm{mg} / \mathrm{kg}$ in the second and third weeks and $6 \mathrm{mg} / \mathrm{kg}$ until the end of treatment, $s c$ ) and water containing $1 \%$ sodium chloride and $0.2 \%$ potassium chloride. The number of rats used is indicated in parentheses. Data are reported as means \pm SEM. ${ }^{*} \mathrm{P}<0.05$ vs NT (two-way ANOVA; factor 1 : hypertension; factor 2: acetylcholine). 
Previous findings have demonstrated an impaired flow-induced vasodilatation in skeletal muscle arterioles from SHR that was due to an impairment of NO-mediated relaxation (11). In addition, aorta from SHR showed impaired endothelium-dependent acetylcholine-induced relaxation that was associated with increased superoxide anion production by NADPH oxidase activity (12).

Rossoni et al. (13) have investigated vascular function in the experimental model of ouabain-induced hypertension in rats. Contrary to that observed in SHR, these investigators demonstrated that treatment with ouabain for 5 weeks was followed by an increase in endothelium-dependent relaxing responses, which reduced the vasoconstrictor response to $\alpha_{1}$-adrenergic stimulation and increased the activity of the $\mathrm{Na}^{+}, \mathrm{K}^{+}$-ATPase in conductance vessels. This effect was mediated by an increase in $\mathrm{NO}$ production related to overexpression of eNOS and nNOS (14). These investigators hypothesized that this adjustment was a compensatory mechanism for the high blood pressure observed in ouabain- treated rats. On the other hand, we also showed that chronic ouabain treatment for 5 weeks increased the expression of pre-pro-endothelin (endothelin-1 precursor) and $\mathrm{ET}_{\mathrm{A}}$ receptor mRNA (15). Furthermore, chronic treatment with BMS182874, an $\mathrm{ET}_{\mathrm{A}}$ receptor antagonist, and losartan, an angiotensin-II type-1 (AT 1 ) receptor antagonist, prevented ouabain-induced hypertension. Interestingly, only BMS 182874 was able to reduce the protein expression of eNOS in the aorta to control levels (15), suggesting that endothelin-1 underlies both hypertension and nitrergic aortic compensatory adjustment in chronic ouabain-treated rats.

Vascular changes induced by chronic ouabain treatment seems to be time- and vascular bed-dependent $(9,16)$. Thus, 5 and 10 weeks of ouabain treatment did not modify the noradrenaline-induced contraction in mesenteric resistance arteries $(9,16)$ while 20 weeks of treatment with this glycoside significantly enhanced the contractile response (9). This effect was correlated with a decline in NO modulation (9) (Figure 2). In addition, we also demonstrated that the

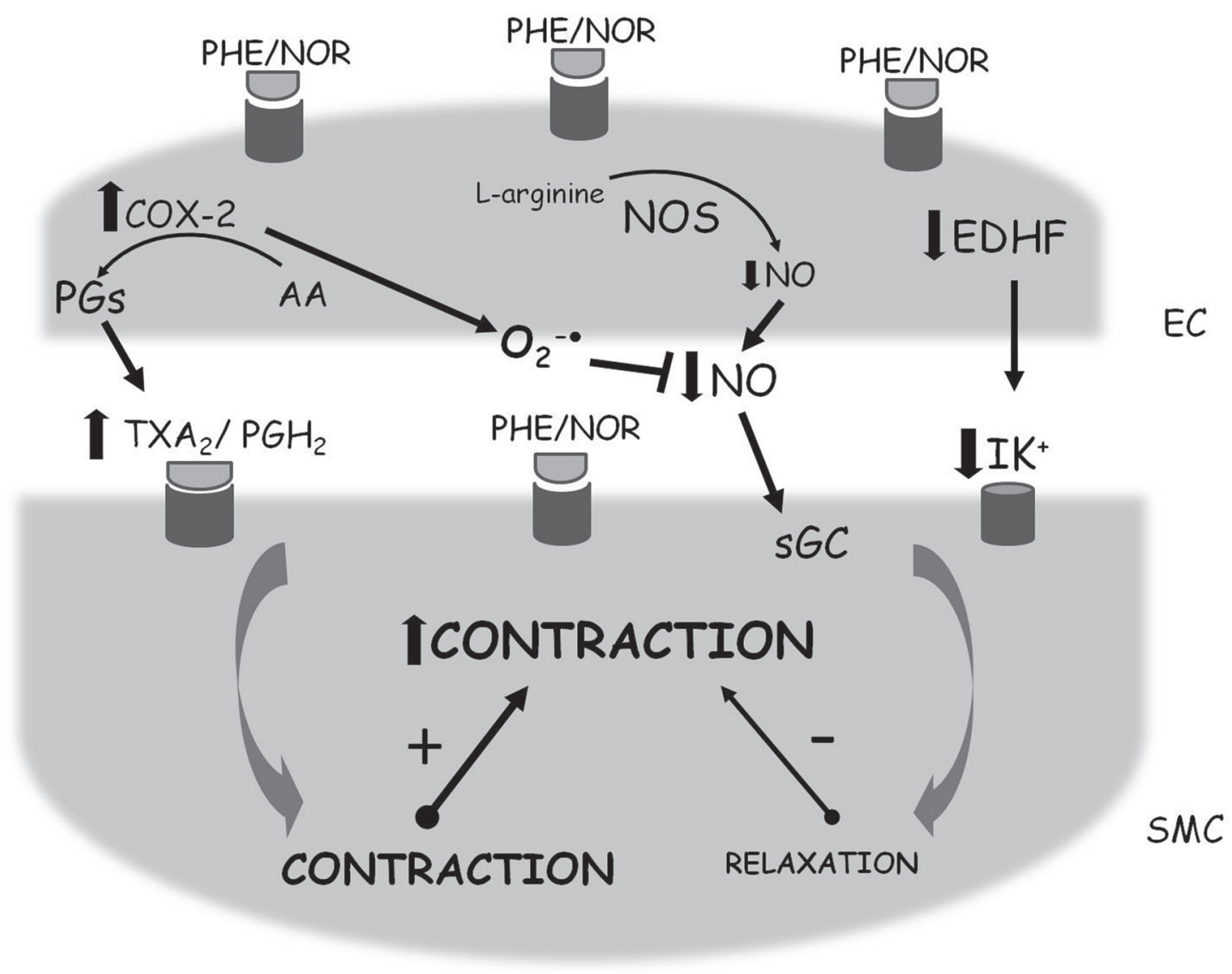

Figure 2. Schematic presentation of the effects elicited by a-adrenoceptor activation in endothelial (EC) and vascular smooth muscle cells (SMC) of small arteries from Wistar rats and spontaneously hypertensive rats (SHR) chronically treated with ouabain. $A A=A r a c h i-$ donic acid; $\mathrm{COX}-2$ = cyclooxygenase-2; $\mathrm{EDHF}=$ endothelium-derived hyperpolarizing factor; $\mathrm{NO}=$ nitric oxide; NOR = noradrenaline; $\mathrm{NOS}=$ nitric oxide synthase; $\mathrm{O}_{2}^{--}=$superoxide anion; $\mathrm{PGH}_{2}=$ prostaglandin $\mathrm{H}_{2} ; \mathrm{PGs}=$ prostaglandins; $\mathrm{PHE}=$ phenylephrine; $\mathrm{sGC}=$ soluble guanylate cyclase; $\operatorname{TxA}_{2}=$ thromboxane $A_{2} . \uparrow=$ increase; $\downarrow=$ decrease; $\rightarrow=$ production and/or stimulation; $Y=$ inhibition. 
treatment of SHR with ouabain for 5 weeks exacerbates the hypertension of SHR associated with a decrease in NO modulation on small arteries (8) (Figure 2).

Previous findings have demonstrated that impaired $\mathrm{NO}$ modulation from DOCA-salt, SHR and ouabain-induced hypertensive rats was not only due to its reduced production. Accelerated degradation by superoxide anion is also observed in these experimental models. In this respect, it has been shown that impaired endothelium-dependent relaxation observed in aorta from DOCA-salt-treated rats was improved by treatment with heparin-binding superoxide dismutase (SOD), a recombinant form of SOD that accumulates in the vascular extracellular matrix and potently scavenges superoxide produced by vascular cells (17). Furthermore, removal of the endothelium significantly reduced superoxide levels in DOCA-salt rats but had no effect in normotensive rats, suggesting that high superoxide production in hypertensive vessels is mainly derived from the endothelium (17). Also, in mesenteric resistance arteries from rats treated with ouabain for 20 weeks, the incubation with SOD restored the enhanced noradrenaline-induced contraction (9), showing the involvement of ROS in this model of hypertension.

NADPH oxidase has been suggested to be the most important superoxide anion source in the vascular wall of DOCA-salt and SHR rats $(12,18)$. Additionally, xanthine oxidase and mitochondria also contribute to vascular superoxide anion generation in hypertensive rats (18). Furthermore, recently our group have published that in mesenteric resistance arteries from ouabain-induced hypertensive rats, COX-2 is the main source of superoxide anion generation (9) (Figure 2).

There is evidence that persisting oxidative stress would render eNOS uncoupling such that it would no longer produce NO, but superoxide anion (19). This situation characterizes eNOS uncoupling when there is a stoichiometric mismatch between eNOS protein levels and NO production. Thus, superoxide anion is generated from the dissociation of the heme ferrous-dioxygen complex in the oxygenase domain of eNOS. The coupling of $\mathrm{BH}_{4}$ to $\mathrm{L}-$ arginine inhibits this production of superoxide anion since $\mathrm{BH}_{4}$ maintains eNOS dimerization and transfers electrons during L-arginine oxidation (19). In agreement with this, in DOCA-salt hypertensive rats, the loss of $\mathrm{BH}_{4}$ induces eNOS uncoupling, resulting in reduced $\mathrm{NO}$ and increased superoxide anion production by this enzyme (20). In this context, NADPH oxidase can further contribute to oxidant stress not only by producing superoxide anion, but also by initiating $\mathrm{BH}_{4}$ oxidation. Oxidative stress may also impair the dimethylarginine dimethylaminohydrolase (DDAH) activity, resulting in increasing levels of asymmetric dimethylarginine (ADMA), an eNOS endogenous inhibitor. In addition, ADMA contributes to eNOS uncoupling and reduces NO production in hypertension (19).

Endothelial dysfunction has also been associated with the endothelial release of vasoconstrictor substances. Accordingly, in vascular smooth muscle from hypertensive animals there is an increase in EDCF-mediated signaling, mostly prostanoids, which play an important role in endothelial dysfunction. The first study suggesting the role of COX and its products in the endothelial dysfunction of SHR was published years after the discovery of the role of the endothelium in the control of vascular tone (21). This study demonstrated that acetylcholine elicited a biphasic response in aorta from SHR: relaxation at the lowest concentrations ( 3 to $100 \mathrm{nM}$ ) and a contractile response at the highest concentrations ( $300 \mathrm{nM}$ to $10 \mu \mathrm{M})$ of this agonist. It is important to emphasize that this response is also seen in mesenteric resistance arteries from SHR (Figure 1B). In line with the investigation of the mechanisms involved in this biphasic response, studies demonstrated that the contraction induced by acetylcholine was abolished by indomethacin, a COX-1/2 inhibitor, and by $\mathrm{Tx} \mathrm{A}_{2} / \mathrm{PGH}_{2}$ (TP) receptor blockers in both aorta and resistance arteries from SHR $(22,23)$.

Studies have shown that the constitutive COX isoform $(C O X-1)$ is the main factor responsible for the acetylcholineinduced contractile response in aorta from $\operatorname{SHR}(21)$, since a specific inhibitor of COX-1 (SC-560), but not COX-2 (NS-398), was able to abolish this contraction. However, other studies have demonstrated that COX-2-derived prostanoids play a fundamental role in the endothelial dysfunction observed in DOCA-salt and ouabain-hypertensive rats $(8,9,24)$.

Recently, we have shown that both indomethacin (a COX-1/2 inhibitor) and NS-398 (a selective COX-2 inhibitor) reduced the hyperreactivity to noradrenaline in mesenteric resistance arteries from rats with 20 -week ouabain-induced hypertension (9). These functional changes were followed by an increase of COX-2 protein expression in mesenteric resistance arteries from ouabain-treated rats (9). Furthermore, incubation with ridogrel (a TxA $\mathrm{A}_{2}$ synthase inhibitor and $\mathrm{PGH}_{2} / \mathrm{TxA}_{2}$ receptor antagonist) decreased the contractile response to noradrenaline in resistance arteries from rats treated with ouabain for 20 weeks, suggesting that $\mathrm{TxA}_{2}$ and/or $\mathrm{PGH}_{2}$ are the major vasoconstrictor prostanoids stimulated by noradrenaline in this hypertension model (Figure 2). Consistent with these results, the tail artery from SHR treated with ouabain for 5 weeks showed enhanced phenylephrine-induced contraction that was associated with $\mathrm{TxA}_{2}$ and/or $\mathrm{PGH}_{2}$ derived from COX-2 metabolism (8) (Figure 2).

The aforementioned studies suggest the involvement of oxidative stress, COX-derived products, and/or reduced $\mathrm{NO}$ bioavailability in endothelial dysfunction in hypertension. Treatment with antioxidant vitamins, NADPH oxidase inhibitors, SOD mimetics, $\mathrm{BH}_{4}$, or $\mathrm{AT}_{1}$ receptor blockers decreases superoxide anion production, improves endothelial function and attenuates the development of hypertension (18). Taken together, these lines of experimental evidence 
(18) underscore the complexity of the interactions among $\mathrm{NO}$, oxidative stress and endothelial dysfunction in hypertension. In addition, our group demonstrated that ouabain, besides inducing oxidative stress and COX-2-derived prostanoid production, increases the release of proinflammatory cytokines in the arteries $(8,9)$. Thus, it may be possible that treatment with anti-inflammatory drugs and/or inhibitors of ouabain action could become a strategy to reduce the vascular damage in refractory hypertension.

\section{Endothelial dysfunction and sympathetic hyperactivity}

Sympathetic hyperactivity is a common feature of cardiovascular diseases and is a relevant predictor of mortality rate in patients with heart failure (25). In heart failure, the increased sympathetic outflow contributes to vasoconstriction and, consequently, to the increment of systemic vascular resistance leading to increased afterload. Elevated afterload further increases cardiac workload and worsens the symptoms of heart failure.

The alterations in vascular tone occurring in heart failure have been linked to endothelial dysfunction. In agreement with this, impairment of endothelium-dependent vasodilatation was demonstrated in heart failure patients, as demonstrated by measurements of forearm blood flow responses to acetylcholine (26). These authors also observed that the blunted vasodilatation in response to acetylcholine was significantly improved by intra-arterial infusion of phentolamine, an $\alpha_{1}$-adrenoceptor antagonist (26). Therefore, an enhanced vascular sympathetic nerve activity could restrain endothelium-mediated vasodilatation in chronic heart failure patients.

Experimentally, coronary artery ligation in rats has been used extensively as a model of chronic left ventricular failure. Using this experimental model, most studies observed an impairment of endothelium-dependent relaxation $(27,28)$. Temporal analysis of endothelial function in aortic rings from myocardial infarcted rats showed that there was no evidence of impaired acetylcholine-induced relaxation after 1 week of coronary artery ligation, with the effect becoming evident only at 4 weeks after myocardial infarction and progressively worsening until week 16 (27). This clearly indicates that endothelial dysfunction in heart failure may depend on its stage with time.

An imbalance between $\mathrm{NO}$ and superoxide anion production leading to enhanced NO inactivation has been associated with endothelial dysfunction in heart failure and appears to be a common feature of many cardiovascular diseases associated with sympathetic hyperactivity (28).

Heart failure patients and rats after myocardial infarction show elevated plasma norepinephrine levels. However, the myocardial infarction caused by coronary artery ligation, in addition to inducing sympathetic overflow, also induces important humoral changes, including activation of the renin-angiotensin-aldosterone system $(29,30)$. Activation of plasma and/or tissue renin-angiotensin-aldosterone system plays a key role in vascular dysfunction in heart failure. In this respect, it was demonstrated that angiotensinconverting enzyme (ACE) inhibitors, $A T_{1}$ receptor blockade and mineralocorticoid receptor antagonists could improve the endothelial dysfunction observed in rats after myocardial infarction $(29,30)$. These beneficial effects of blockade of the renin-angiotensin-aldosterone system on endothelial function were accompanied by decreased superoxide anion generation and they are at least part of the mechanism associated with improvement of vasomotor function in heart failure animals $(29,30)$.

Cardiovascular effects of sympathetic overflow can also be mimicked by sustained infusion of low doses of catecholamine, with the activation of adrenoceptors being, in this case, the first signaling event. Moreover, it is known that $\beta$-adrenergic stimulation could activate the renin-angiotensin-aldosterone system. The administration of isoproterenol, a non-selective $\beta$-adrenoceptor agonist, to laboratory animals for several days is used as a model of prolonged $\beta$-adrenoceptor stimulation. In the vasculature of these animals, we demonstrated that isoproterenol treatment increases the vasoconstrictor response to the $\alpha_{1}$-adrenoceptor agonist phenylephrine as well as to the serotonin (5-HT) agonist in rat (31) and mouse (Figure 3A) aorta, although no changes in acetylcholine-induced relaxation were observed $(31,32)$. In addition, endothelial removal and L-NAME incubation normalized the hyperreactivity to phenylephrine observed in aortas from isoproterenol-treated rats, indicating that persistent activation of $\beta$-adrenoceptors impairs basal endothelial-derived $\mathrm{NO}(31,32)$. The reduction of basal $\mathrm{NO}$ availability induced by isoproterenol was not related to a reduction in eNOS activity. Indeed, eNOS activity and protein expression were found to be significantly enhanced in aortas from isoproterenol-treated rats (31). However, chronic isoproterenol treatment enhanced superoxide anion levels, measured by hydroethydine fluorescence in situ in rat (31) and mouse aorta (Figure 3B). Thus, an exacerbated inactivation of basal NO by superoxide anion can be responsible for the increased constrictor reactivity of aortas induced by chronic treatment with isoproterenol. Accordingly, incubation of aortic rings with SOD restored the responsiveness to phenylephrine in rat (31) and mouse aorta from isoproterenol-treated animals (Figure 3A).

The maladaptive effects of chronic activation of $\beta$-adrenoceptors were unexpected, since it is known that acute administration of $\beta$-adrenoceptor agonists, including isoproterenol, induces vasorelaxation by activation of an adenylyl cyclase-cAMP-PKA pathway, that causes hyperpolarization and decreases the sensitivity of myofilaments to $\mathrm{Ca}^{2+}$. In addition, activation of $\beta$-adrenoceptors on the endothelium stimulates synthesis of NO by eNOS (33) (Figure 4). However, it has been demonstrated that overexpression of eNOS could paradoxically be maladaptive by leading 
A

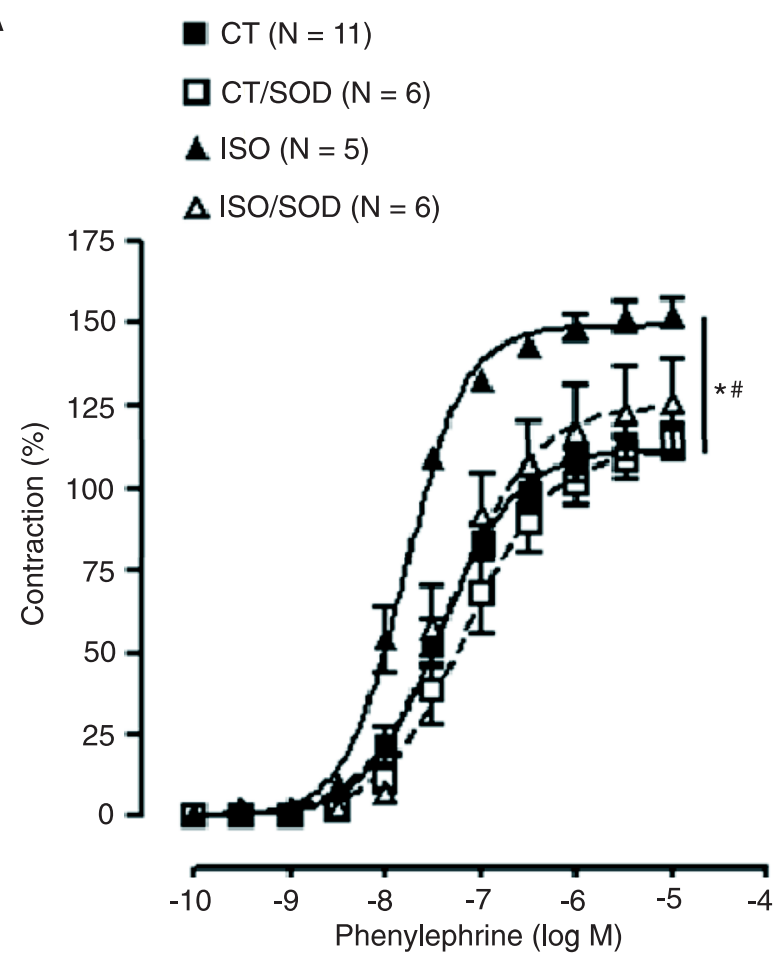

B
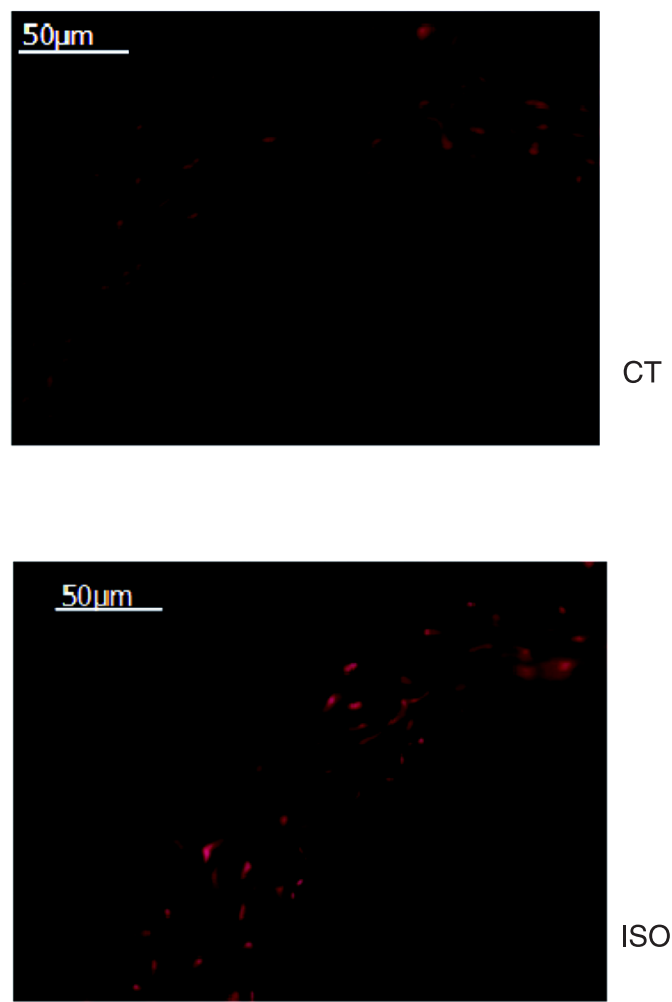

Figure 3. Effect of 7-day isoproterenol treatment on vascular function and superoxide generation in mouse aorta. $A$, Contraction response to phenylephrine in aortas with endothelium from control (CT) and isoproterenol (ISO)-treated FVB mice. Superoxide dismutase (SOD) incubation $(150 \mathrm{U} / \mathrm{mL} ; 30 \mathrm{~min})$ restored the contractile response to phenylephrine of isoproterenol-treated rats. Data are reported as a percentage of the response to $75 \mathrm{mM} \mathrm{KCl}$ in each aortic ring. Data are reported as means \pm SEM. ${ }^{*} \mathrm{P}<0.05$ ISO vs $\mathrm{CT}$; \#P < 0.05 ISO vs ISO/SOD (two-way ANOVA). B, Representative fluorescence photomicrographs of slices of aorta from CT and ISO-treated FVB mice. Vessels were labeled with the oxidative dye hydroethidine, which produces a red fluorescence when oxidized to ethidium bromide by superoxide anion.

to oxidative stress through synthesis of superoxide anion (19). In agreement with this hypothesis, we demonstrated that aortas from isoproterenol-treated animals present an increased activity and protein expression of eNOS and nNOS; in addition, L-arginine supplementation was able to normalize the hyperreactivity to phenylephrine (31). Thus, sustained $\beta$-adrenoceptor activation could exacerbate eNOS activity and expression, but, in turn, cause eNOS uncoupling that would become a source of superoxide anion production (Figure 4). In addition, aortas from rats with heart failure induced by coronary artery ligation show increased eNOS mRNA and protein expression associated with high superoxide anion levels (28). It is noteworthy that other sources of superoxide anion generation such as NADPH oxidase and xanthine oxidase have been suggested to be activated in blood vessels from rats and patients with heart failure $(28,29)$.

It has been proposed that, in association with oxidative stress, an increased production of cytokines and other mediators of inflammation has a pathological role in generating and/or worsening endothelial dysfunction in many cardiovascular diseases. It is known that cytokines such as interleukin (IL)-1 $\beta$ could impair the endotheliumdependent relaxation in resistance arteries (34). We previously demonstrated that isoproterenol treatment for 7 days significantly enhanced mRNA and protein expression of IL-1 $\beta$ and IL- 6 and the activity of the nuclear factor kappa B (NF-KB) in aortic homogenates (35). Interestingly, suppression of NF-KB activity via oral treatment with thalidomide improved the hyperreactivity to phenylephrine observed in isoproterenol-treated rats (35). Thus, anti-inflammatory drugs emerge as a therapeutic approach to treat endothelial disorders in cardiovascular diseases associated with sympathetic overflow.

Therefore, there is convincing evidence suggesting that reduced NO bioavailability following sympathetic hyperactivity and/or increased plasma catecholamine levels is the major contributor to endothelial dysfunction. Generation of superoxide anion by uncoupled eNOS and inflammatory mediator synthesis induced by chronic $\beta$-adrenergic activa- 
tion seem to play a central role in the endothelial dysfunction induced by sympathetic overflow. Thus, both mechanisms may be therapeutic targets for cardiovascular diseases associated with endothelial dysfunction and sympathetic hyperactivity.

\section{Endothelial dysfunction in diabetes mellitus}

Diabetes mellitus (DM) is currently considered to be the major epidemic of the century and a public health problem worldwide. In the 1980s it was estimated that 30 million individuals had DM worldwide. This number increased to 135 million in 1995, reaching 173 million in 2002, and 300 million people have been predicted to develop DM by 2030 (36). Approximately two-thirds of these patients live in developing countries, where the epidemic is most intense, with increasing proportions of affected individuals among younger age groups. DM has been associated with high mortality and a high incidence of cardiovascular complications, which account for about $70 \%$ of all deaths in patients with DM. The incidence, prevalence and mortality of cardiovascular disease, such as myocardial infarction, stroke, hypertension, atherosclerosis, and heart failure are approximately 3-5 times higher among diabetic than nondiabetic subjects (36).

Alterations in vascular function are considered to be factors closely related to the development and/or maintenance of cardiovascular complications in patients with DM and may occur even in the early stages of the disease. Although the nature of the pathogenic link between elevated circulating levels of glucose and cardiovascular complications is a source of debate, it is clearly recognized that hyperglycemia is responsible for the pathogenesis of vascular complica-

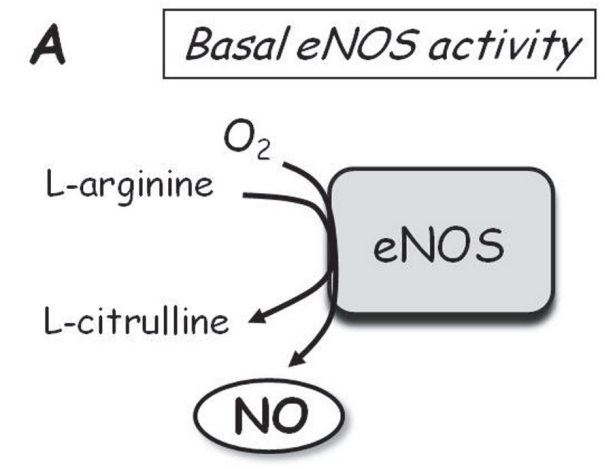

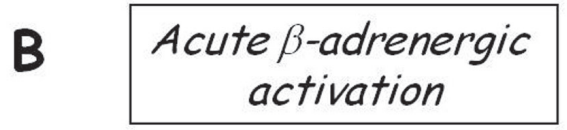

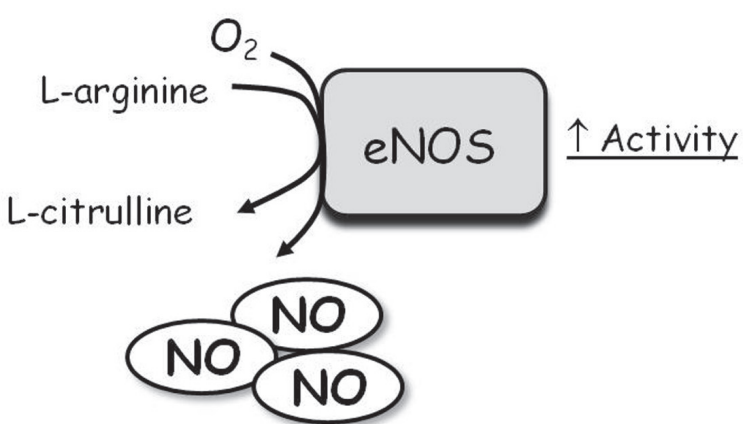

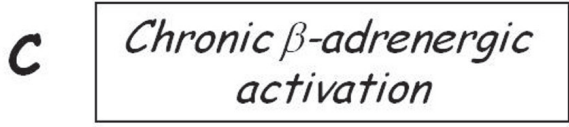

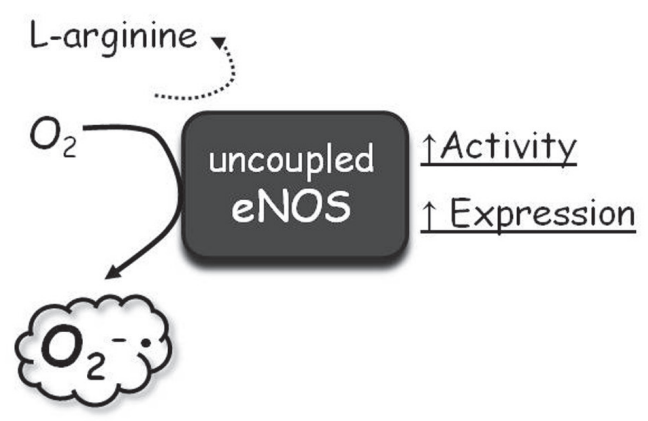

Figure 4. Schematic presentation of the effect of acute and chronic $\beta$-adrenergic activation on endothelial nitric oxide synthase (eNOS) activity, expression and uncoupling. $A$, In normal vessels, basal eNOS activity oxidizes L-arginine, producing L-citrulline and nitric oxide (NO) at physiological rates, contributing to vascular tone maintenance. $B$, Acute $\beta$-adrenergic activation induced by $\beta$-adrenoceptor agonists induces eNOS activity and could increased endothelial NO release. $C$, Sustained elevated catecholamine levels could induce overactivation of $\beta$-adrenoceptors that enhance activity and protein expression of eNOS but, in turn, eNOS becomes uncoupled, generating superoxide anion $\left(\mathrm{O}_{2}^{--}\right)$. 
tions associated with DM. It has been demonstrated that acute or chronic hyperglycemia can cause several changes in vascular function, including a decrease in endotheliumdependent relaxation (37-39), an increased contractile response of vascular smooth muscle $(38,40,41)$ and a predisposition to the development of inflammatory, thrombotic and atherosclerotic events (42).

The progression of vascular disease in DM is largely related to endothelial dysfunction mechanisms. Impaired endothelium-dependent vasodilatation has been demonstrated in various vascular beds of different animal models of DM and in human patients with types 1 and 2 DM (37-39). Under these conditions there is vasoconstriction, increased adhesion of platelets and leukocytes, an uncontrolled growth of cells, especially smooth muscle in the vessel wall, an increase in lipids depots in the subendothelium, and an increased tendency to develop vascular thrombosis. The mechanisms associated with these events may be multiple and include changes in synthesis, release, diffusion, or degradation of various factors produced by endothelial cells. In $\mathrm{DM}$, endothelial dysfunction is not a homogeneous process in its characteristics and distribution, but it varies depending on the duration of the exposure to hyperglycemia and on the vascular bed evaluated $(37,41)$. Several mechanisms have been proposed to explain the endothelial functional abnormalities associated with the exposure of the vascular tissue to hyperglycemia. The increased activity of the polyol pathway, nonenzymatic glycation of proteins with the production of advanced glycation endproducts (AGEs), oxidative stress, with an increase in ROS production, and alterations in protein kinase $\mathrm{C}$ (PKC) are mentioned in the literature as the main mechanisms involved in endothelial dysfunction and atherogenesis, preceding the above-mentioned vascular complications in patients with DM.

The most notable characteristic of endothelial dysfunction associated with DM is the vascular NO reduction. Multiple mechanisms are involved in this effect, but increased oxidative stress seems to be the first alteration that triggers several others. The importance of oxidative stress in mediating the vascular complications of DM is supported by studies showing that antioxidants such as vitamin $C$ and $E$ or SOD correct the endothelium-dependent vasodilator function in humans, in experimental models of DM or in arteries exposed to high glucose (42). Hyperglycemia induces oxidative stress by increasing superoxide anion production by the mitochondrial electron transport chain and activation of NADPH-dependent oxidases (42).

In the presence of hyperglycemia, the increased superoxide production leads to formation of peroxinitrites (ONOO-), which may react with the co-factor for $\mathrm{NOS}, \mathrm{BH}_{4}$, leading to its degradation. In diabetic rats, reduced levels of $\mathrm{BH}_{4}$ have been reported. According to these results, $\mathrm{BH}_{4}$ supplementation to diabetic rats improves the endotheliumdependent relaxation, suggesting that uncoupled eNOS plays a role in diabetic endothelial dysfunction (39). As previously described, oxidative stress may also impair DDAH activity, resulting in increasing levels of ADMA. These results therefore suggest that, in addition to its increased degradation, NO synthesis may be decreased by vascular tissue exposure to hyperglycemia.

The sensitivity of vascular smooth muscle may be reduced even with an adequate supply of NO. Vascular studies in humans and in animal models of DM have commonly used NO donors or nitrovasodilators (e.g., sodium nitroprusside) as a control for the study of endothelium-dependent vasodilatation. These agents act directly on vascular smooth muscle resulting in an endothelium-independent vasodilation. Evidence suggests that the vascular smooth muscle sensitivity to $\mathrm{NO}$ is reduced in diabetes and in arteries exposed to hyperglycemia in vitro, indicating that hyperglycemia interferes with the activation of guanylate cyclase by NO (43). On the other hand, other studies have suggested increased production of $\mathrm{NO}$, or increased sensitivity of vascular smooth muscle cells to NO, in diabetes.

As described above, endothelial dysfunction could also be related to the release of vasoconstrictor substances. In vessels of diabetics there is an increase in endotheliumdependent vasoconstrictor mechanisms, mostly mediated by prostanoids, which play an important role in endothelial dysfunction. For example, in mesenteric and coronary arteries from diabetic dogs, exogenous arachidonic acid induces $\mathrm{TxA}_{2}$-mediated contraction. In contrast, arachidonic acid leads to $\mathrm{PGI}_{2}$-mediated relaxation in the arteries of controls (44). Additionally, a reduction in the relaxation induced by acetylcholine in diabetic aortas, mesenteric and femoral arteries is corrected by COX inhibitors (45). An increased participation of vasoconstrictor prostanoids in the arteries of diabetic rats, such as $\mathrm{TxA}_{2}$ and $\mathrm{PGF}_{2 \alpha}$ has also been reported $(41,46)$. Thus, TP receptor antagonism can restore the impaired relaxation and prevent the endothelium-dependent contraction in arteries exposed to hyperglycemia $(41,46)$. $T x A_{2}$ plays a role not only in the reduction of endothelial function in type $1 \mathrm{DM}$, but may also be involved in the enhanced contractile response to vasoconstrictor agents (41).

Hyperglycemia selectively increases the expression of COX-2 without affecting COX-1 levels, leading to increased release of vasoconstrictor prostanoids (45). The mechanisms by which hyperglycemia leads to COX-2 overexpression are not clear. However, accumulating evidence indicates that ROS activates specific redox-sensitive signal transduction pathways and transcriptional regulatory events that increase COX-2 expression in the vascular wall (45). In support of this view, it has been reported that, under high exposure to glucose, endothelial cells increase the production of superoxide anion, which was primarily responsible for the enhanced COX-2 expression (47). Hyperglycemia not only modifies the profile of prostanoids, leading to alteration of vasomotor tone, but also increases the release of arachidonic acid by vascular cells (46). 
It has been shown that the concentration of diacylglycerol (DAG) in hyperglycemia is elevated in vascular cells and tissues. It increases through the acylation of triose intermediates generated by glycolysis, which leads to the synthesis of fatty acids and subsequent acylation of glycerol. DAG is a co-factor, which is rate limiting for PKC (48). PKC and phospholipids generated by calcium-activated phospholipase $\mathrm{A}_{2}(\mathrm{cPLA})$ regulate several vascular functions such as cell growth, permeability, contractility, and extracellular matrix protein synthesis. In diabetes, activation of PKC induces an increase in vascular smooth muscle contractility (40) and expression of NADPH oxidase, resulting in ROS generation (42) and decreased $\mathrm{Na}^{+}, \mathrm{K}^{+}$-ATPase activity (49). However, we have recently reported that diabetic aorta is also associated with increased $\mathrm{Na}^{+}, \mathrm{K}^{+}$-ATPase activity, an effect, which is also mediated by PKC (50). In these arteries,
$\mathrm{TxA}_{2} / \mathrm{PGH}_{2}$ released by COX-2 activates $\mathrm{PKC} \beta \mathrm{II}$, which in turn increases $\mathrm{Na}^{+}, \mathrm{K}^{+}$-ATPase activity (Figure 5 ). This is possibly a counter-regulatory mechanism to the vascular dysfunction present in this artery.

Hyperglycemia is also associated with increased production of AGEs that play a role in endothelial dysfunction associated with DM. Through activation of their receptor, AGEs increase production of ROS via NADPH oxidase (51). Activation of these receptors, when linked to monocytes/ macrophages, also initiates important processes for tissue remodeling. The cellular connection of AGE proteins induces cellular responses such as enhanced production of cytokines, growth factors, laminin, fibronectin, and collagen type IV in mesangial cells via PDGF synthesis, as well as increased angiogenesis in endothelial cells. Hyperglycemia can lead to sorbitol accumulation via aldose reductase and

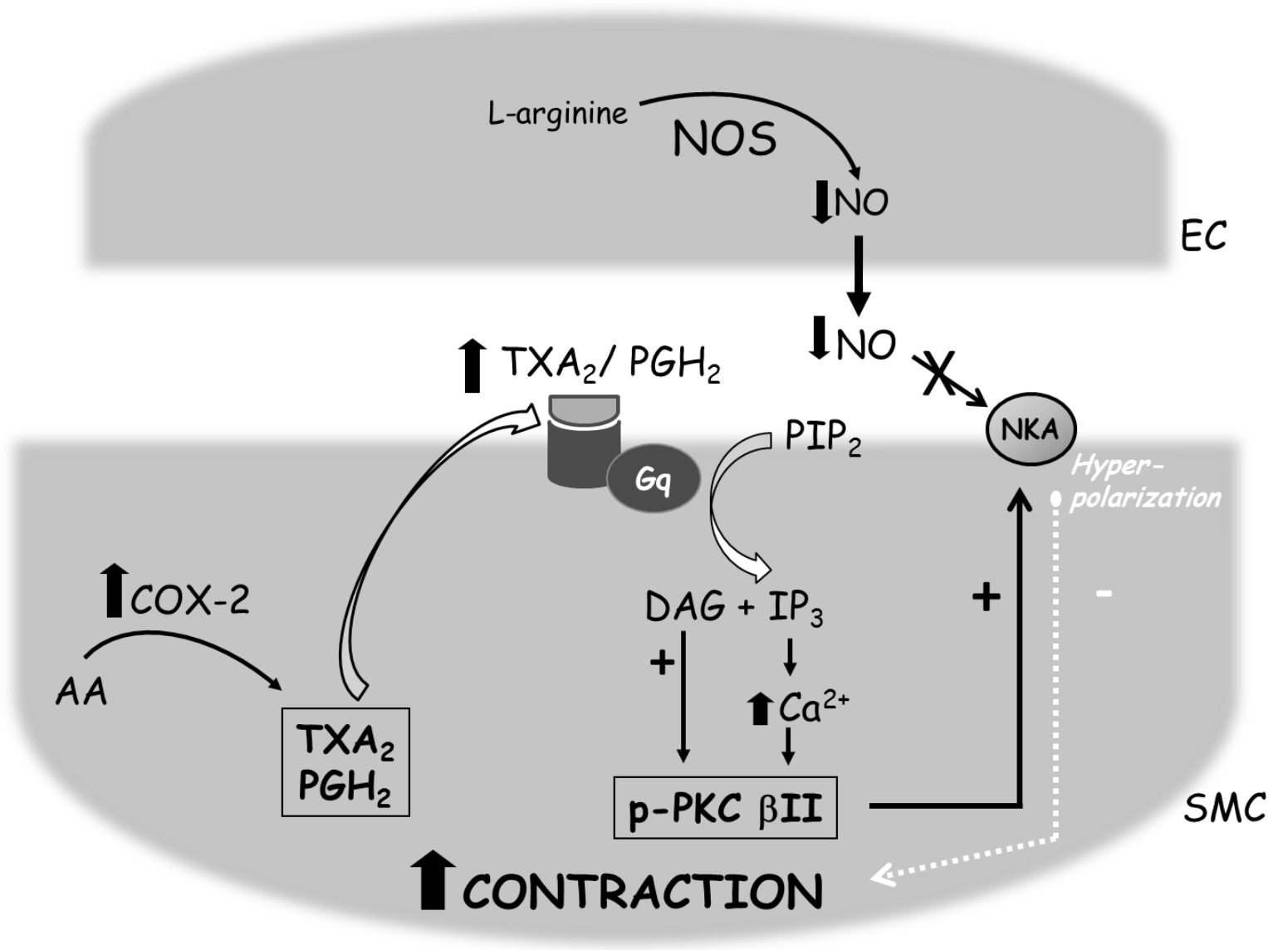

Figure 5. Schematic presentation of the proposed signal transduction pathway involved in altered $\mathrm{Na}^{+}, \mathrm{K}^{+}$-ATPase activity induced by type I diabetes in aorta. The model shows vascular smooth muscle cell (SMC) containing the catalytic $\alpha$-isoform of $\mathrm{Na}^{+}, \mathrm{K}^{+}-\mathrm{ATPase}$ (NKA) and the abolished effect of endothelium-derived nitric oxide (NO) on this enzyme. Increased protein levels of cyclooxygenase-2 (COX-2) in SMC elevated prostanoid $\left(\mathrm{TxA}_{2}\right.$ and $\left.\mathrm{PGH}_{2}\right)$ synthesis and their autocrine activity via $\mathrm{TxA}_{2} / \mathrm{PGH}_{2}$ receptor enhances the phosphorylated $\beta$ II isoform of PKC (p-PKC $\beta I I)$, which increases vascular contractility but in turn activates NKA. EC = Endothelial cell; $\mathrm{DAG}=$ diacylglycerol; $\mathrm{IP}_{3}=$ inositol trisphosphate; $\mathrm{PIP}_{2}=$ phosphatidylinositol 4,5 -bisphosphate. $\uparrow=$ increase; $\downarrow=$ decrease; $\rightarrow=$ production and/or stimulation; dotted white line with arrow pointing downwards = inhibition. 
sorbitol can be converted into fructose by sorbitol dehydrogenase. This increased flow causes elevation of osmotic pressure, decreases the myoinositol concentration and, together with glycolysis, changes the intracellular redox balance.

Therefore, understanding the physiological mechanisms involved in vascular disorders resulting from hyperglycemia is essential for the proper use of available therapeutic resources.

\section{Obesity and endothelial dysfunction}

The prevalence of obesity is on the rise and has reached epidemic proportions. Obesity is characterized by excessive fat accumulation that may impair health. In fact, the excessive accumulation of adipose tissue in the upper body, so-called central or visceral obesity, has a major role in the development of obesity-related metabolic and cardiovascular disorders, such as insulin resistance, impaired glucose tolerance, dyslipidemia, and elevated blood pressure (52). Therefore, risk factors for cardiovascular disease coexist in obese people and the installation of these diseases begins when the risk factors induce endothelial dysfunction.

Despite the fact that obesity-related disorders can individually impair endothelial function, visceral adiposity also affects endothelial function. The severity of endothelial dysfunction correlates with the degree of visceral adiposity (52). Adipocytes and adipose tissue-derived macrophages secrete several factors capable of directly affecting endothelial function. Such factors are called adipokines, and comprise cytokines, chemokines, and hormone-like proteins, such as tumor necrosis factor-alpha (TNF- $\alpha$ ), IL-6, leptin, angiotensin-II, plasminogen activator inhibitor-1, resistin, and monocyte chemoattractant protein-1 (52). Uncontrolled secretion of adipokines by obese hypertrophic adipocytes promotes a systemic inflammatory state, which contributes to cardiovascular diseases.

Besides visceral adipose tissue, increased fat depots around blood vessels also contribute to endothelial dysfunction. Perivascular adipose tissue has been shown to release vasodilator and vasoconstrictor factors and also a variety of adipokines (53). Although during initial steps of diet-induced obesity perivascular adipose tissue-derived leptin induces an adaptive NO overproduction, contributing to preserving vascular function, obese perivascular adipose tissue-derived adipokines appear to promote local inflammation (53). This process, together with systemic inflammation, can contribute to alterations of endothelial function. Moreover, we have recently demonstrated an increase in TNF- $\alpha$ protein expression directly in perivascular adipose tissue-cleaned aorta from mice with high-fat diet-induced obesity (54). Whether systemic and perivascular adipose tissue-induced inflammation is involved in the induction of TNF- $\alpha$ expression in vascular cells is not yet known. Whatever the source of inflammatory factors, however, the endothelium may be negatively affected by proinflammatory cytokines. The exact visceral and perivascular adipose tissue-derived factors implicated in endothelial dysfunction in obesity are not known, but TNF- $\alpha$ and IL- 6 have emerged as possible candidates (55).

It has been demonstrated that cytokines impair endothelial function, manifested as a reduced NO-dependent relaxation (34). TNF- $\alpha$-induced endothelial dysfunction can be due to a reduced NO production by inhibition of eNOS gene expression in endothelial cells. Similarly to the TNF- $\alpha$ effect, reduction of eNOS expression was observed in aorta from mice with high-fat diet-induced obesity, which exhibit increased inflammatory markers (54). Obesity modifies post-translational eNOS regulation that results also in reduced NO production. Reduced eNOS phosphorylation (ser 1177) via phosphatidylinositol 3-kinase/ Akt (56) and uncoupled eNOS (57) are related to impaired endothelium-dependent relaxation in obesity. Moreover, protein expression of caveolin-1, which inhibits eNOS activity in endothelial cells via protein-protein interactions, is increased in aorta from rats with diet-induced obesity (58). Thus, a reduced NO production is involved in the impaired endothelium-dependent relaxation in obese animals, but how obesity modifies transcriptional and post-translational eNOS regulation is still unclear.

Proinflammatory cytokines not only reduce NO production, but also decrease its bioavailability due to increased ROS bioavailability. Several sources of ROS, such as NADPH oxidase, xanthine oxidase, uncoupled eNOS, and mitochondrial respiratory chain, can be stimulated by proinflammatory cytokines in endothelial cells (52). It is well established that oxidative stress is implicated in endothelial dysfunction in the obese condition. Incubation with compounds that quench ROS, such as SOD and tiron, restores the reduced endothelium-dependent relaxation in arteries of obese animals $(54,57)$. Although increased vascular cell-produced ROS can be observed in arteries of obese animals (57), obese perivascular adipose tissue-derived ROS can have a paracrine action on the vascular wall and impair the endothelium-dependent relaxation (53). Obesity can also impair the vascular antioxidant capacity. We have demonstrated a decrease in Cu/Zn-SOD protein expression, which could contribute to a decrease in antioxidant capacity and consequently superoxide anion accumulation in the aorta from mice with high-fat-induced obesity (54). Therefore, increase in ROS levels, together with reduced NO production, represent at least part of the mechanism underlying endothelial dysfunction in obesity.

In addition to reducing $\mathrm{NO}$ bioavailability, increased ROS levels can also promote inflammation. The NF-kB family members are important redox-sensitive transcriptional factors that regulate transcription of genes that encode inflammatory cytokines, adhesion molecules, chemokines, iNOS, and COX-2 (55). In turn, many products of NF-kB-regulated genes activate NF-kB, which exacerbates the inflammatory 
status by producing ROS and additional cytokines, worsening the pathological processes and leading to endothelial dysfunction. Many of these products of NF-KB activation impact the endothelium-dependent relaxation, such as TNF- $\alpha$, as described earlier, and the enzyme COX-2 (55). Indeed, an increase in COX-2 protein expression is observed in arteries from obese rats, which contributes to reduced endothelium-dependent vasodilation $(57,59)$. Thus, inhibition of NF-KB may be able to restore the obesity-induced endothelial dysfunction.

The NF-kB pathway appears to be up-regulated in vascular cells from obese individuals. Endothelial cells from obese humans presented elevated NF-kB expression when compared to lean adults (60). Moreover, we have observed a reduction in $\mathrm{K} B$ protein expression in the aorta from obese mice (54). Although NF-KB is thought to play a role in mediating endothelial dysfunction in obesity, there are a few studies showing direct evidence of NF-KB contribution to this condition. Oral administration of salsalate (nonacetylated salicylate) for 4 days inhibits NF-kB in venous endothelial cells and improves flow-mediated endothelium-dependent relaxation in the brachial artery of non-diabetic overweight/ obese middle-aged humans (60). Moreover, inhibition of NF-kB also reduces adipocyte-induced adhesion molecule expression in human umbilical venous endothelial cells. Similarly, we have demonstrated a correction of the reduced endothelium-dependent relaxation in obese mice by incubating aortic rings with salicylate (54). This finding suggests the direct participation of the NF-KB pathway in the impaired endothelium-dependent relaxation in obese mice. Taken together, data from these studies demonstrate the direct participation of the up-regulated NF-KB pathway in vascular cells from obese subjects, which could contribute to vascular inflammation and endothelial dysfunction.

The specific mechanism by which inhibition of vascular $\mathrm{NF}-\mathrm{KB}$ restores endothelial dysfunction in obesity is also not clear. In endothelial cells, NF-KB activation is associated with an increase in NADPH oxidase-derived superoxide levels. Since both inhibition of NF-KB activity and antioxidant compounds showed similar effects on endothelium-dependent vasodilation $(54,60)$, inhibition of NF-KB might improve endothelial function by reducing ROS levels. However, the sequence of events leading to endothelial dysfunction still needs to be elucidated, including the possibilities that NF-KB could increase ROS availability or that ROS could activate NF-KB.

It is clear that systemic and local inflammation associated with oxidative stress is implicated in endothelial dysfunction in obesity. Many pharmacotherapies (e.g., glitazones, fibrates, metformin, and statins) and even weight loss, which have a cardioprotective effect, reduce systemic inflamma- tion, at least in part by inhibiting inflammatory signaling in adipocytes. A direct effect of vascular NF-KB activation appears to make an important contribution to this condition, which may be partially mediated by oxidative stress. Additional studies aimed at elucidating specific mechanisms of endothelial function impairment by NF-KB would most likely support vascular NF-KB as a crucial target in a therapeutic strategy to treat obesity-induced cardiovascular disease.

\section{Conclusion}

In conclusion, endothelial dysfunction is a hallmark of most cardiovascular and endocrine/metabolic diseases. It is induced by complex changes in the balance between EDRF and EDCF production, bioavailability and action in smooth muscle cells. Reduction of NO bioavailability due to impaired NO synthesis by eNOS, increased oxidative stress and eNOS uncoupling are common mechanisms underlying endothelial dysfunction in many cardiovascular and endocrine diseases. In addition, COX-2-derived prostanoids and pro-inflammatory cytokines could be overproduced in hypertension, diabetes and obesity. Although much is known about the importance of endothelial dysfunction in the pathophysiology of cardiovascular diseases, these diseases still have a high mortality worldwide. Thus, further research of the vascular pathophysiology of cardiovascular diseases is needed in order to determine exact tools for a proper treatment in each case.

Finally, the present review reinforces the importance of anti-inflammatory drugs (e.g., NF-kB and COX-2 inhibitors) and eNOS co-factors (e.g., $\mathrm{BH}_{4}$ ) as an effective pharmacotherapy strategy to improve endothelial dysfunction present in classical cardiovascular diseases associated with sympathetic hyperactivity such as heart failure and hypertension, and also in endocrine/metabolic disorders including type I and II diabetes and obesity. In addition, drugs that chronically inhibit the vascular action of ouabain represent a strategy for reducing vascular damage in refractory hypertension. The potential beneficial effects of these drugs on endothelial function could be effective in improving the local control of vascular tone in worldwide cardiovascular and metabolic diseases.

\section{Acknowledgments}

Research supported by FAPESP and CNPq. C.F. Wenceslau and H.T. Oliveira are supported by a PhD fellowship from CNPq, and G.K. Couto is supported by a PhD fellowship from FAPESP. L.V. Rossoni, E.H. Akamine and F.E. Xavier are recipients of research fellowships from CNPq. 


\section{References}

1. Furchgott RF, Zawadzki JV. The obligatory role of endothelial cells in the relaxation of arterial smooth muscle by acetylcholine. Nature 1980; 288: 373-376.

2. Rapoport RM, Draznin MB, Murad F. Endothelium-dependent relaxation in rat aorta may be mediated through cyclic GMP-dependent protein phosphorylation. Nature 1983; 306: 174-176.

3. Ignarro LJ, Buga GM, Wood KS, Byrns RE, Chaudhuri G. Endothelium-derived relaxing factor produced and released from artery and vein is nitric oxide. Proc Natl Acad Sci U S A 1987; 84: 9265-9269.

4. Palmer RM, Ashton DS, Moncada S. Vascular endothelial cells synthesize nitric oxide from L-arginine. Nature 1988; 333: 664-666.

5. Alp NJ, Channon KM. Regulation of endothelial nitric oxide synthase by tetrahydrobiopterin in vascular disease. Arterioscler Thromb Vasc Biol 2004; 24: 413-420.

6. Ministério da Saúde. Portal da Saúde. http://portal.saude.gov.br/ portal/aplicacoes/noticias/default.cfm?pg=dspDetalheNoticia\&id_ area=124\&CO_NOTICIA=11290. Accessed April 1, 2011.

7. Konishi M, Su C. Role of endothelium in dilator responses of spontaneously hypertensive rat arteries. Hypertension 1983; 5: 881-886.

8. Xavier FE, Davel AP, Fukuda LE, Rossoni LV. Chronic ouabain treatment exacerbates blood pressure elevation in spontaneously hypertensive rats: the role of vascular mechanisms. J Hypertens 2009; 27: 1233-1242.

9. Wenceslau CF, Davel AP, Xavier FE, Rossoni LV. Long-term ouabain treatment impairs vascular function in resistance arteries. J Vasc Res 2011; 48: 316-326.

10. Taddei S, Virdis A, Mattei P, Salvetti A. Vasodilation to acetylcholine in primary and secondary forms of human hypertension. Hypertension 1993; 21: 929-933.

11. Koller A, Huang A. Impaired nitric oxide-mediated flowinduced dilation in arterioles of spontaneously hypertensive rats. Circ Res 1994; 74: 416-421.

12. Zalba G, Beaumont FJ, San Jose G, Fortuno A, Fortuno MA, Etayo JC, et al. Vascular NADH/NADPH oxidase is involved in enhanced superoxide production in spontaneously hypertensive rats. Hypertension 2000; 35: 1055-1061.

13. Rossoni LV, Salaices M, Marin J, Vassallo DV, Alonso MJ. Alterations in phenylephrine-induced contractions and the vascular expression of $\mathrm{Na}^{+}, \mathrm{K}^{+}$-ATPase in ouabain-induced hypertension. Br J Pharmacol 2002; 135: 771-781.

14. Rossoni LV, Salaices M, Miguel M, Briones AM, Barker LA, Vassallo DV, et al. Ouabain-induced hypertension is accompanied by increases in endothelial vasodilator factors. $A m \mathrm{~J}$ Physiol Heart Circ Physiol 2002; 283: H2110-H2118.

15. Xavier FE, Yogi A, Callera GE, Tostes RC, Alvarez Y, Salaices $\mathrm{M}$, et al. Contribution of the endothelin and renin-angiotensin systems to the vascular changes in rats chronically treated with ouabain. Br J Pharmacol 2004; 143: 794-802.

16. Xavier FE, Rossoni LV, Alonso MJ, Balfagon G, Vassallo DV, Salaices M. Ouabain-induced hypertension alters the participation of endothelial factors in alpha-adrenergic responses differently in rat resistance and conductance mesenteric arteries. Br J Pharmacol 2004; 143: 215-225.

17. Somers MJ, Mavromatis K, Galis ZS, Harrison DG. Vascular superoxide production and vasomotor function in hyperten- sion induced by deoxycorticosterone acetate-salt. Circulation 2000; 101: 1722-1728.

18. Touyz RM. Reactive oxygen species, vascular oxidative stress, and redox signaling in hypertension: what is the clinical significance? Hypertension 2004; 44: 248-252.

19. Forstermann U. Nitric oxide and oxidative stress in vascular disease. Pflugers Arch 2010; 459: 923-939.

20. Landmesser U, Dikalov S, Price SR, McCann L, Fukai T, Holland SM, et al. Oxidation of tetrahydrobiopterin leads to uncoupling of endothelial cell nitric oxide synthase in hypertension. J Clin Invest 2003; 111: 1201-1209.

21. Luscher TF, Vanhoutte PM. Endothelium-dependent contractions to acetylcholine in the aorta of the spontaneously hypertensive rat. Hypertension 1986; 8: 344-348.

22. Gluais P, Paysant J, Badier-Commander C, Verbeuren T, Vanhoutte PM, Feletou M. In SHR aorta, calcium ionophore A-23187 releases prostacyclin and thromboxane A2 as endothelium-derived contracting factors. Am J Physiol Heart Circ Physiol 2006; 291: H2255-H2264.

23. Lang MG, Noll G, Luscher TF. Effect of aging and hypertension on contractility of resistance arteries: modulation by endothelial factors. Am J Physiol 1995; 269: H837-H844.

24. Adeagbo AS, Zhang X, Patel D, Joshua IG, Wang Y, Sun X, et al. Cyclo-oxygenase-2, endothelium and aortic reactivity during deoxycorticosterone acetate salt-induced hypertension. J Hypertens 2005; 23: 1025-1036.

25. Barretto AC, Santos AC, Munhoz R, Rondon MU, Franco FG, Trombetta IC, et al. Increased muscle sympathetic nerve activity predicts mortality in heart failure patients. Int J Cardiol 2009; 135: 302-307.

26. Santos AC, Alves MJ, Rondon MU, Barretto AC, Middlekauff HR, Negrao CE. Sympathetic activation restrains endothelium-mediated muscle vasodilatation in heart failure patients. Am J Physiol Heart Circ Physiol 2005; 289: H593-H599.

27. Teerlink JR, Clozel M, Fischli W, Clozel JP. Temporal evolution of endothelial dysfunction in a rat model of chronic heart failure. J Am Coll Cardiol 1993; 22: 615-620.

28. Bauersachs J, Bouloumie A, Fraccarollo D, Hu K, Busse $\mathrm{R}$, Ertl G. Endothelial dysfunction in chronic myocardial infarction despite increased vascular endothelial nitric oxide synthase and soluble guanylate cyclase expression: role of enhanced vascular superoxide production. Circulation 1999; 100: 292-298.

29. Sartorio CL, Fraccarollo D, Galuppo P, Leutke M, Ertl G, Stefanon I, et al. Mineralocorticoid receptor blockade improves vasomotor dysfunction and vascular oxidative stress early after myocardial infarction. Hypertension 2007; 50: 919925.

30. Schafer A, Fraccarollo D, Tas P, Schmidt I, Ertl G, Bauersachs J. Endothelial dysfunction in congestive heart failure: ACE inhibition vs angiotensin II antagonism. Eur J Heart Fail 2004; 6: 151-159.

31. Davel AP, Kawamoto EM, Scavone C, Vassallo DV, Rossoni LV. Changes in vascular reactivity following administration of isoproterenol for 1 week: a role for endothelial modulation. Br J Pharmacol 2006; 148: 629-639.

32. Fukuda LE, Davel AP, Verissimo-Filho S, Lopes LR, Cachofeiro V, Lahera V, et al. Fenofibrate and pioglitazone do not ameliorate the altered vascular reactivity in aorta of 
isoproterenol-treated rats. J Cardiovasc Pharmacol 2008; 52: 413-421.

33. Ferro A, Queen LR, Priest RM, Xu B, Ritter JM, Poston L, et al. Activation of nitric oxide synthase by beta 2-adrenoceptors in human umbilical vein endothelium in vitro. $\mathrm{Br} J$ Pharmacol 1999; 126: 1872-1880.

34. Jimenez-Altayo F, Briones AM, Giraldo J, Planas AM, Salaices M, Vila E. Increased superoxide anion production by interleukin-1 beta impairs nitric oxide-mediated relaxation in resistance arteries. J Pharmacol Exp Ther 2006; 316: 42 52.

35. Davel AP, Fukuda LE, De Sa LL, Munhoz CD, Scavone C, Sanz-Rosa D, et al. Effects of isoproterenol treatment for 7 days on inflammatory mediators in the rat aorta. $A m \mathrm{~J}$ Physiol Heart Circ Physiol 2008; 295: H211-H219.

36. Murray CJ, Lopez AD. Mortality by cause for eight regions of the world: Global Burden of Disease Study. Lancet 1997; 349: 1269-1276.

37. Pieper GM. Enhanced, unaltered and impaired nitric oxidemediated endothelium-dependent relaxation in experimental diabetes mellitus: importance of disease duration. Diabetologia 1999; 42: 204-213.

38. Davel AP, Rossoni LV, Vassallo DV. Effects of ouabain on the pressor response to phenylephrine and on the sodium pump activity in diabetic rats. Eur J Pharmacol 2000; 406: 419-427.

39. Akamine EH, Kawamoto EM, Scavone C, Nigro D, Carvalho $\mathrm{MH}$, de Cassia AT, et al. Correction of endothelial dysfunction in diabetic female rats by tetrahydrobiopterin and chronic insulin. J Vasc Res 2006; 43: 309-320.

40. Abebe W, MacLeod KM. Protein kinase C-mediated contractile responses of arteries from diabetic rats. $\mathrm{Br} \mathrm{J}$ Pharmacol 1990; 101: 465-471.

41. Xavier FE, Davel AP, Rossoni LV, Vassallo DV. Time-dependent hyperreactivity to phenylephrine in aorta from untreated diabetic rats: role of prostanoids and calcium mobilization. Vascul Pharmacol 2003; 40: 67-76.

42. Cohen RA, Tong X. Vascular oxidative stress: the common link in hypertensive and diabetic vascular disease. J Cardiovasc Pharmacol 2010; 55: 308-316.

43. Chan NN, Vallance P, Colhoun HM. Endothelium-dependent and -independent vascular dysfunction in type 1 diabetes: role of conventional risk factors, sex, and glycemic control. Arterioscler Thromb Vasc Biol 2003; 23: 1048-1054.

44. Gimeno AL, Sterin-Borda L, Borda ES, del Castillo EJ, Gimeno MF. Arachidonate evokes constriction of coronary and mesenteric arteries isolated from diabetic dogs. Adv Prostaglandin Thromboxane Leukot Res 1983; 12: 235240.

45. Bagi Z, Erdei N, Papp Z, Edes I, Koller A. Up-regulation of vascular cyclooxygenase-2 in diabetes mellitus. Pharmacol Rep 2006; 58 (Suppl): 52-56.

46. Tesfamariam B, Brown ML, Deykin D, Cohen RA. Elevated glucose promotes generation of endothelium-derived vasoconstrictor prostanoids in rabbit aorta. J Clin Invest 1990; 85: 929-932.

47. Cosentino F, Eto M, De Paolis P, van der Loo B, Bachschmid $\mathrm{M}$, Ullrich $\mathrm{V}$, et al. High glucose causes upregulation of cyclooxygenase- 2 and alters prostanoid profile in human endothelial cells: role of protein kinase $C$ and reactive oxygen species. Circulation 2003; 107: 1017-1023.

48. Wild S, Roglic G, Green A, Sicree R, King H. Global prevalence of diabetes: estimates for the year 2000 and projections for 2030. Diabetes Care 2004; 27: 1047-1053.

49. Xia P, Kramer RM, King GL. Identification of the mechanism for the inhibition of $\mathrm{Na}^{+}, \mathrm{K}^{+}$-adenosine triphosphatase by hyperglycemia involving activation of protein kinase $\mathrm{C}$ and cytosolic phospholipase A2. J Clin Invest 1995; 96: 733740.

50. Gallo LC, Davel AP, Xavier FE, Rossoni LV. Time-dependent increases in ouabain-sensitive $\mathrm{Na}^{+}, \mathrm{K}^{+}$-ATPase activity in aortas from diabetic rats: The role of prostanoids and protein kinase C. Life Sci 2010; 87: 302-308.

51. Wautier MP, Chappey O, Corda S, Stern DM, Schmidt AM, Wautier JL. Activation of NADPH oxidase by AGE links oxidant stress to altered gene expression via RAGE. Am J Physiol Endocrinol Metab 2001; 280: E685-E694.

52. Sturm W, Sandhofer A, Engl J, Laimer M, Molnar C, Kaser $S$, et al. Influence of visceral obesity and liver fat on vascular structure and function in obese subjects. Obesity 2009; 17 : 1783-1788.

53. Eringa EC, Bakker W, Smulders YM, Serne EH, Yudkin JS, Stehouwer CD. Regulation of vascular function and insulin sensitivity by adipose tissue: focus on perivascular adipose tissue. Microcirculation 2007; 14: 389-402.

54. Kobayasi R, Akamine EH, Davel AP, Rodrigues MA, Carvalho CR, Rossoni LV. Oxidative stress and inflammatory mediators contribute to endothelial dysfunction in high-fat diet-induced obesity in mice. J Hypertens 2010; 28: 21112119.

55. Kralisch S, Sommer G, Stangl V, Kohler U, Kratzsch J, Stepan $\mathrm{H}$, et al. Secretory products from human adipocytes impair endothelial function via nuclear factor kappaB. Atherosclerosis 2008; 196: 523-531.

56. Zecchin HG, Priviero FB, Souza CT, Zecchin KG, Prada PO, Carvalheira JB, et al. Defective insulin and acetylcholine induction of endothelial cell-nitric oxide synthase through insulin receptor substrate/Akt signaling pathway in aorta of obese rats. Diabetes 2007; 56: 1014-1024.

57. Lobato NS, Filgueira FP, Akamine EH, Davel AP, Rossoni LV, Tostes RC, et al. Obesity induced by neonatal treatment with monosodium glutamate impairs microvascular reactivity in adult rats: Role of NO and prostanoids. Nutr Metab Cardiovasc Dis 2010 [doi: 10.1016/j.numecd.2010.02.006].

58. Yang N, Ying C, Xu M, Zuo X, Ye X, Liu L, et al. High-fat diet up-regulates caveolin-1 expression in aorta of diet-induced obese but not in diet-resistant rats. Cardiovasc Res 2007; 76: 167-174.

59. Sanchez A, Contreras C, Martinez P, Villalba N, Benedito $S$, Garcia-Sacristan A, et al. Enhanced cyclooxygenase 2-mediated vasorelaxation in coronary arteries from insulinresistant obese Zucker rats. Atherosclerosis 2010; 213: 392-399.

60. Pierce GL, Lesniewski LA, Lawson BR, Beske SD, Seals DR. Nuclear factor-\{kappa\}B activation contributes to vascular endothelial dysfunction via oxidative stress in overweight/ obese middle-aged and older humans. Circulation 2009; 119: $1284-1292$. 